\title{
O processo de reconhecimento das indicações geográficas de alimentos e bebidas brasileiras: regulamento de uso, delimitação da área e diferenciação do produto
}

\author{
The process of geographical indications recognition for food and beverages in Brazil: \\ regulation of use, delimitation aerea and product differentiation
}

\author{
Maria Emília Rodrigues Valente ${ }^{\mathrm{I}^{*}}$ Ronaldo Perez $^{\mathrm{I}}$ \\ Lucia Regina Rangel de Moraes Valente Fernandes ${ }^{I I}$
}

RESUMO

As denominações de origem e as indicações de procedência compõem as espécies de indicação geográfica (IG) previstas pela legislação brasileira e têm sido vistas como formas de mobilização e valorização dos territórios e de agregação de valor aos produtos típicos e de qualidade diferenciada. O presente trabalho teve como objetivo caracterizar a condução das etapas de elaboração do regulamento de uso, delimitação da área e comprovação da notoriedade e da relação entre produto e meio geográfico das IGs brasileiras. A metodologia adotada foi pesquisa survey, realizada por meio de questionários semiestruturados. Os resultados revelaram que, apesar das lacunas da legislação brasileira sobre IGs, vários órgãos têm viabilizado o processo de construção das IGs brasileiras atuando de forma decisiva nas etapas de elaboração do regulamento de uso (universidades, ONGs, INPI), delimitação da área (universidades, Embrapa, Emater, IMA), comprovação da notoriedade (SEBRAE) e da relação entre meio geográfico e qualidade (universidades). A comprovação da influência do território nas características qualitativas do produto constitui, atualmente, o principal entrave ao desenvolvimento das denominações de origem no País.

Palavras-chave: propriedade intelectual, denominação de origem, indicação de procedência, conhecimento tradicional, legislação.

\section{ABSTRACT}

The appellations of origin and indication of source are species of geographical indication (GI) provided by the Brazilian industrial property law that could be seen as one of the ways of mobilization and recovering of the rural territories adding value to local products with differentiated quality. This study aimed to characterize the stages of the construction of the regulations of use of GI, the geographical area delimitation, the evidence of reputation and the relationship between product and geographical environment of GIs in Brazil. The survey research was the methodology adopted conducted through semi-structured questionnaires. The results showed that despite the shortcomings of the Brazilian legislation on GIs, several organs has enabled the construction process of the Brazilian GIs acting decisively on the elaboration steps of the regulation of use (universities, NGOs, INPI), on the area delimitation (universities , Embrapa, Emater, IMA), on the evidence of reputation (SEBRAE) and on the relationship between geographical environment and quality (universities). The proof of the influence of the geographical environment on the product qualitative characteristics is currently the main obstacle to the development of appellations of origin in the country.

Key words: intellectual property, appellation of origin, indication of source, traditional knowledge, legislation.

\section{INTRODUÇÃO}

Denominação de origem (DO) e indicação de procedência (IP) compõem as duas modalidades de indicações geográficas (IGs) previstas no Brasil pela Lei de Propriedade Industrial (Lei n.9279, de 14 de maio de 1996) e têm sido vistas como formas de mobilização e valorização dos territórios e de agregação de valor aos produtos típicos e de qualidade diferenciada. Ao Instituto Nacional de Propriedade Industrial (INPI), foi delegada, pela referida lei, a responsabilidade pelo estabelecimento das condições de registro, o que é tratado na Resolução n.75/2000 do INPI (INPI, 2000). Essa Resolução lista uma série de documentos necessários para o reconhecimento e

IDepartamento de Tecnologia de Alimentos, Universidade Federal de Viçosa (UFV), Campus Universitário, 36570-000, Viçosa, MG, Brasil. E-mail: maria.valente@ufv.br.*Autor para correspondência.

IIInstituto Nacional da Propriedade Industrial (INPI), Rio de Janeiro, RJ, Brasil. 
registro das IGs, entre eles o regulamento de uso do nome geográfico, o instrumento oficial que delimita a área geográfica, descrição do produto ou serviço que se devam exclusivamente ao meio geográfico e à comprovação da notoriedade.

O regulamento de uso de uma IG consiste em uma série de regras definidas e acordadas entre os produtores estabelecidos dentro da área delimitada pela IG, as quais deverão ser seguidas para que eles possam usar a IG em seus produtos (BRASIL, 2008). A extensão da área de abrangência deve delimitar, com a máxima precisão possível, o território onde se produz o produto original (INPI \& SEBRAE, 2011). A base territorial para obter o direito de usar uma IG deve estar estreitamente relacionada com a especificidade do produto e seu vínculo com a origem geográfica. Ela representa também o principal limite do sistema, já que não permite que nenhum outro produtor externo à área delimitada utilize a IG (FAO \& SINERGI, 2010).

A comprovação da notoriedade é requerida para processos de IP e pode abordar aspectos como história do desenvolvimento do produto, documentos, publicações, entrevistas, entre outros (INPI \& SEBRAE, 2011). A descrição das qualidades e características do produto ou do serviço que se devam, exclusiva ou essencialmente, ao meio geográfico é somente requerida para processos de DO, que, segundo CERDAN (2009), apoia-se sobre as provas de unicidade do produto, ou seja, de que um produto jamais poderá ser igual se produzido fora da sua região de origem.

Informações a respeito do processo vivenciado por entidades que obtiveram reconhecimento de IP ou DO são escassas e difusas na literatura brasileira, embora sejam de suma importância para o desenvolvimento das IGs no País. Essa carência de pesquisas relacionadas ao processo de preparo do dossiê motivou o desenvolvimento do presente trabalho, que teve como objetivo realizar um levantamento junto às entidades brasileiras, titulares e requerentes de IGs, a fim de caracterizar a condução das etapas de elaboração do regulamento de uso, delimitação da área da IG e comprovação da notoriedade e da relação entre produto e meio geográfico por elas vivenciada.

\section{MATERIAL E MÉTODOS}

As etapas de elaboração do regulamento de uso, delimitação da área geográfica e comprovação de notoriedade e da relação entre produto e meio geográfico foram analisadas por meio de dados primários, obtidos de questionários semiestruturados aplicados por telefone, correio eletrônico ou pessoalmente e respondidos por profissionais que colaboraram para a concretização das etapas ou por representantes das instituições requerentes e titulares das IGs.

Entre as regiões que se encaixavam no escopo do presente estudo no período de realização deste (áreas geográficas produtoras de gêneros alimentícios ou bebidas que possuíam ou buscavam, através de suas entidades requerentes, o registro de IG junto ao INPI), foram consideradas somente aquelas que não se encontravam em situação de dependência de cumprimento de exigência até 10 outubro de 2010. Responsáveis pela elaboração do regulamento de uso das seguintes regiões responderam ao questionário: Vale dos Vinhedos, Região do Cerrado Mineiro, Paraty, Pampa Gaúcho da Campanha Meridional, Pinto Bandeira, Litoral Norte Gaúcho, Região de Salinas, Serro e Canastra. Responsáveis pela comprovação da reputação ou qualidade específica (associada ao meio geográfico) das seguintes regiões responderam ao questionário: Vale dos Vinhedos, Paraty, Pampa Gaúcho da Campanha Meridional, Pinto Bandeira, Litoral Norte Gaúcho, Região de Salinas, Serro, Canastra e Pelotas. Responsáveis pela delimitação da área das seguintes regiões responderam ao questionário: Vale dos Vinhedos, Paraty, Pampa Gaúcho da Campanha Meridional, Pinto Bandeira, Litoral Norte Gaúcho, Região de Salinas, Serro e Canastra.

Dados secundários, obtidos a partir de regulamentos de uso disponibilizados pelo Conselho Regulador de IGs e de cópias reprográficas dos pedidos de registro encaminhados ao INPI, foram também consultados e analisados.

Os dados obtidos foram tabulados e analisados mediante uso de técnicas de estatística descritiva, com o auxílio dos softwares SPSS (Statistical Package for the Social Sciences), versão 13.0 for Windows e Microsoft Excel 2007.

\section{RESULTADOS E DISCUSSÃO}

\section{Elaboração do regulamento de uso}

A definição do regulamento de uso é uma questão complexa, uma vez que cada regra estabelecida implica risco de exclusão, seja por requisitos geográficos, seja pelas exigências técnicas, que podem acarretar custos e investimentos adicionais para produtores. Entretanto, 10\% das associações declararam não ter tido orientação externa na elaboração do regulamento; as $90 \%$ restantes afirmaram ter sido orientadas por órgãos 
governamentais parceiros, e na maioria das vezes houve o envolvimento de mais de uma instituição simultaneamente. Instituições de ensino e pesquisa foram predominantes nessa etapa; organizações não governamentais (ONGs), INPI e órgãos estaduais, também foram citados.

Segundo os entrevistados, o fator mais levado em conta na definição das normas do regulamento de uso foi a tradição produtiva da região - saber-fazer local -, tendo sido citado em 73\% dos casos. No entanto, a literatura relata o conflito existente entre o saber-fazer e inovações técnicas destinadas a melhorias na qualidade do produto. No Brasil, tem-se verificado a extinção de cultivares de uvas tradicionalmente produzidas em função da padronização de conhecimentos e práticas produtivas (NIERDELE, 2011).

O regulamento de uso de IGs nacionais ou estrangeiras foi utilizado como modelo para 87,5\% das entidades entrevistadas, tendo constituído a principal base para a construção de $75 \%$ dos regulamentos. IGs brasileiras pioneiras, como Vale dos Vinhedos e Paraty, foram mencionadas, assim como a Resolução n.75/00 do INPI, publicações acadêmicas e legislações específicas.

A legislação brasileira é omissa em termos da procedência da matéria-prima para produtos com IG, porém 55,5\% das entidades pesquisadas determinaram que $100 \%$ deverão ser provenientes do interior da região delimitada. É interessante notar que a procedência da matéria prima tem sido um fator limitante ao desenvolvimento das IGs. Produtores de espumantes de Garibaldi, município situado na Serra Gaúcha, iniciaram a construção de uma IP, mas foram compelidos a reorientar seus esforços para a criação de uma Marca de Certificação, pois, embora apresentasse condições propícias (reputação) para a construção de uma IG, o município não possui uma área vitícola considerável, de modo que a maior parte da uva é proveniente de outros municípios adjacentes. Em vista dessa situação, alguns atores consideraram inadequado levar adiante o projeto (NIERDELE \& VITROLLES, 2010).

A maioria (66,6\%) dos regulamentos de uso estabelece restrições em relação às variedades (vegetais) e às raças (animais). Segundo NIERDELE \& VITROLLES (2010), uma das definições mais importantes do regulamento de uso de uma IG para vinhos diz respeito às cultivares autorizadas, sendo essa determinação uma forma de buscar identidade e tipicidade para os produtos.

De fato, embora não seja o único fator, a definição de variedades ou raças específicas pode limitar a participação de produtores inseridos da área delimitada. Nas IGs consolidadas, observou-se que, em todos os casos, há situações em que produtores, cujas propriedades se encontram localizadas dentro da região delimitada, não foram enquadrados no perfil das IGs, porque o processo produtivo não atendia às exigências do regulamento de uso, por vezes demasiadamente rígidas - como no caso do Pampa Gaúcho da Campanha Meridional, onde são permitidas somente as raças Angus e Hereford, ou cruzas entre elas. Em metade dos casos, produtores foram excluídos porque os produtos não atendiam ao padrão de qualidade estabelecido, ou porque não eram associados da entidade. Esta última constatação é polêmica, à medida que o agrupamento instituído pela legislação como requerente da IG não é o titular da IG. Segundo BRUCH et al. (2010), a entidade é uma representante legal da coletividade, sendo a IG um direito extensivo a todos os produtores ou prestadores de serviço que estejam na área demarcada e que explorem o produto, objeto da indicação. Sendo assim, desde que o produtor respeite as normas estabelecidas, ele tem o direito de se beneficiar da IG. A falta de interesse foi apontada por um dos entrevistados como motivo para que alguns produtores não usassem a IG. O desconhecimento por parte dos consumidores brasileiros em relação às IGs, e, consequentemente, sua pouca valorização no mercado nacional, é, possivelmente, um fator que contribui para essa falta de interesse.

Cerca de $70 \%$ dos entrevistados mencionaram que questões tecnológicas constituíram um entrave ao processo de construção do regulamento de uso, porém apenas $14 \%$ consideraram que essas questões representaram o principal entrave. Considerando-se que o regulamento é constituído de uma série de normas técnicas e que nem todos os produtores incluídos na região delimitada elaboram seus produtos exatamente da mesma forma, mesmo que haja um "saber-fazer” predominante, é compreensível que questões tecnológicas tenham se constituído no entrave mais citado. A dificuldade de adaptação a inovações tecnológicas introduzidas, em algumas situações, em detrimento aos saberes locais, pode também ser um fator que tenha contribuído para o resultado observado.

Embora as questões tecnológicas tenham sido citadas como a dificuldade mais comumente encontrada, o dispêndio excessivo de tempo (em média, 16 meses) foi apontado como a principal dificuldade encontrada na elaboração do regulamento em $43 \%$ dos casos. Por se tratar de um processo cujo objetivo é o estabelecimento de regras 
e por haver, na maioria dos casos, participação de número expressivo de pessoas, é compreensível que haja dispêndio considerável de tempo, já que muitas reuniões são necessárias para essa finalidade. Além disso, uma entidade revelou ter gasto cerca de 48 meses na construção do regulamento, devido à realização de um trabalho simultâneo, visando à reestruturação das unidades produtivas e melhoria da qualidade dos produtos. Por outro lado, uma associação afirmou ter gasto apenas um mês na elaboração do regulamento, já que o número de associados era reduzido.

A falta de informações a respeito de como elaborar o regulamento de uso foi apontada, em $29 \%$ dos casos, como a principal dificuldade encontrada. No entanto, observou-se que esse fator foi mencionado, em sua maioria, pelas IGs pioneiras no País, uma vez que iniciaram o processo de reconhecimento quando o assunto era ainda pouco conhecido no Brasil e a regulamentação sobre o tema estava em estágio inicial. Vinte e dois por cento dos entrevistados declararam não ter havido dificuldades na elaboração do regulamento.

Delimitação da área das indicações geográficas

As IGs são extremamente distintas em termos da área delimitada. A IP "Paraty" abrange apenas parte de um único município (Paraty), enquanto a IP Vale do Submédio do São Francisco inclui 83 municípios de Estados distintos da Bahia e Pernambuco; a IP Vale dos Vinhedos possui apenas $72,45 \mathrm{~km}^{2}$, enquanto a IP Região do Cerrado Mineiro possui $125755 \mathrm{~km}^{2}$.

Instituições de ensino e pesquisa, com destaque para as universidades, são as maiores colaboradoras na delimitação da área das IGs. Essa parceria entre entidades requerentes e universidades é especialmente forte na região Sul do País, onde também é expressiva a participação da Embrapa. A participação da Emater e do Instituto Mineiro de Agropecuária (IMA) é mais relevante em Minas Gerais. Há certa peculiaridade neste Estado, uma vez que existe uma política de identificação de regiões cafeicultoras e produtoras de queijo, iniciada antes mesmo da consolidação da IG como forma de direito de propriedade industrial. Prova disso é a Portaria n.165, de 27 de abril de 1995, que delimita as regiões produtoras de café do Estado de Minas Gerais para a instituição do certificado de origem. Outros órgãos vêm contribuindo para a delimitação das áreas de IG, seja com recursos financeiros, seja com apoio técnico, como o MAPA, MDA, SEBRAE, ONGs, entre outros.
Embora a Resolução n.75/00 do INPI estabeleça que o pedido de registro de uma IG deve conter um instrumento oficial que delimite a área geográfica e que deve ser expedido pelo órgão competente de cada Estado, nota-se que outras entidades, principalmente universidades, vêm se responsabilizando por essa etapa. Em consonância com o observado, DA SILVA et al. (2010) defendem que a condução de pesquisas e estudos científicos justifica a participação de professores universitários, pesquisadores e estudantes que realizam teses, dissertações e trabalhos científicos relacionados com o tema.

A delimitação pode ser distinta entre os casos, dependendo de fatores como a espécie de IG pretendida (IP ou DO), do grau de transformação e dos fatores que conferem o diferencial ao produto. Fatores humanos - "saber-fazer", tradição, tipicidade - constituíram o principal fundamento utilizado na delimitação da área de 42\% das IGs estudadas. Fatores naturais - clima, solo, vegetação, relevo, hidrografia - foram os mais relevantes na delimitação de $25 \%$ dos casos, e a qualidade dos produtos, associada a fatores naturais ou humanos, foi usada como principal critério na delimitação de $33 \%$ dos casos.

De modo geral, observou-se que $89 \%$ das demarcações foram baseadas em fatores naturais e humanos e 78\%, na qualidade dos produtos. Nota-se, portanto, estreita ligação entre esses três fatores na delimitação da área. Em muitos dos casos, observouse que o levantamento histórico e cultural serviu de base para a delimitação, uma vez que contém elementos que trazem à tona a tradição produtiva da região, a situação socioeconômica antiga e atual, entre outros, fornecendo, ainda que de forma robusta, um ponto de partida para estudos mais aprofundados para a delimitação da área. Fatores políticos, como a união entre um grupo de produtores, fronteiras políticas, situação socioeconômica, antiga e atual, localização dos produtores e de zonas urbanas, também foram citados como fundamentos utilizados na delimitação da área da IG.

Em metade dos casos, zoneamentos resultantes de estudos anteriores auxiliaram no processo de delimitação das IGs. No caso da região do Pampa Gaúcho da Campanha Meridional, por exemplo, mapas de composição florística foram extremamente importantes. Nas IGs Região do Cerrado Mineiro, Serro e Canastra, zoneamentos realizados pelo IMA auxiliaram na delimitação. No Vale dos Vinhedos, a região demarcada como IP serviu como base para a nova delimitação da DO. 
Cabe destacar que a legislação brasileira é omissa sobre a transformação de uma IP para uma DO e sobre o cancelamento de uma IG. Segundo BRUCH (2008), não há disposição legal para afirmar se uma IG pode ser anulada ou extinta no Brasil, do que se presume que, uma vez reconhecida, esta o será ad eternum. Sob este ponto de vista, a IP e a DO "Vale dos Vinhedos” poderiam coexistir.

A falta de elementos geográficos bem determinados - fruto da indisponibilidade de estudos prévios sobre fatores naturais, como clima, solo, relevo, vegetação - foi apontada como a maior dificuldade na delimitação da área, tendo sido citada por $50 \%$ dos entrevistados. Esse fator foi especialmente importante para a demarcação de áreas com DO, uma vez que é uma exigência a comprovação da relação do meio geográfico com a qualidade do produto. Nesses casos, a delimitação da área deve ser feita de forma mais criteriosa, o que exige, portanto, conhecimento profundo das características naturais da região. A análise dos dados (processamento, elaboração de mapas) foi a principal dificuldade encontrada em 25\% das situações, e o tempo despendido na demarcação da área (visitas às propriedades, comprovação in loco de zoneamentos de composição de solos, vegetação, entre outros) foi a mais importante em $12,5 \%$ dos casos. Influências políticas e custos elevados foram citados como dificuldades secundárias que ocorreram em uma das situações pesquisadas. Um entrevistado responsável pela delimitação de uma das IGs declarou não ter encontrado nenhuma espécie de dificuldade. A presença marcante de instituições de apoio possivelmente é responsável por essa relativa facilidade encontrada nesta etapa no processo.

\section{Diferenciação do produto da região}

Embora para a IP seja exigido que se comprove a notoriedade e para DO que se comprove que a qualidade se deve ao meio geográfico (fatores naturais e humanos), as duas noções estão bastante interligadas. É muito comum encontrarmos tanto notoriedade quanto uma qualidade particular no produto que não se encontra em nenhum outro produto de fora de seu território (VELLOSO et al., 2010).

Não é estabelecido pela legislação brasileira um limite de tempo para se considerar que um produto tenha ou não reputação, isto é, a história do produto pode ser antiga ou recente na área considerada. A região do Cerrado Mineiro, por exemplo, possui uma história recente na cafeicultura. Esta se desenvolveu somente na década de 1970 e o reconhecimento da qualidade se deu apenas na década de 90, quando os cafés da região começaram a ser sucessivamente premiados no concurso anual "Prêmio Brasil de Qualidade do Café para Espresso”, organizado pela torrefadora italiana Illycafè. Além disso, a qualidade do café dessa região se deu através de inovações tecnológicas, como uso de irrigação, e não por meio da utilização das técnicas tradicionalmente utilizadas na cafeicultura (VALENTE, 2011).

A notoriedade atual do produto foi citada por $91 \%$ dos entrevistados como um fator que diferencia o produto das regiões pesquisadas dos similares produzidos em outras regiões. A notoriedade antiga, ou seja, a história do produto naquela região, a influência dos fatores naturais (clima, solo, relevo, vegetação) nas características do produto, o saber-fazer e a qualidade do produto de forma geral foram citados por $64 \%$ dos entrevistados como fatores diferenciadores do produto. A produção em pequena escala foi citada como o diferencial em $55 \%$ dos casos; a produção artesanal, em 45\% das situações; e a notoriedade internacional, ou seja, o reconhecimento no mercado externo, em 18\% dos questionários respondidos.

Embora não esteja explícito na legislação brasileira, a notoriedade ainda é um dos princípios básicos das IGs, pois foi esse elemento que fez com que surgissem as primeiras IGs protegidas pela lei. Hoje, todavia, não há impedimentos para que este caminho ocorra de forma inversa, ou seja, que seja primeiro registrada uma DO para que então esta adquira maior notoriedade, mas alguma notoriedade a DO deve possuir, posto que, do contrário, estaria se utilizando isso mais como uma estratégia de marketing para promover o local e seu produto ou serviço do que, necessariamente, o objeto de se proteger uma DO: evitar a sua usurpação (VELLOSO et al., 2010).

Várias foram as formas utilizadas para comprovar a notoriedade das regiões. Dados econômicos - histórico de arrecadação de ICMS, índice comparativo de preços - foram utilizados por todas as entidades, assim como a reunião de reportagens de jornais e revistas de diferentes âmbitos de circulação. Documentos antigos, registros oficiais e livros foram também bastante utilizados, assim como fotografias, antigas e atuais, e entrevistas com agentes locais (moradores, produtores, comerciantes). Relatos, lendas e poemas foram utilizados em menor número, bem como a premiação em concursos de qualidade para comprovar a boa fama dos produtos. A existência de festas tradicionais, como o Festival Mundial da Cachaça, em Salinas, e de cursos superiores (Tecnólogo Produção de Cachaça) 
foram outros meios de comprovação de tradição e notoriedade utilizados.

Metade dos entrevistados afirmou encontrar dificuldade no levantamento histórico e cultural da região. Destes, $80 \%$ declararam que o tempo despendido no processo foi a principal causa da dificuldade, uma vez que a pesquisa realizada em bibliotecas, principalmente de documentos antigos, que não podem ser retirados do recinto nem fotocopiados, é um trabalho árduo e absorve tempo. A entrevista com agentes locais também foi apontada como um trabalho demorado. Os $20 \%$ restantes declararam que a ausência de material (documentos, livros) foi a causa da dificuldade encontrada no levantamento histórico e cultural da região.

Em 72,7\% dos casos, houve auxílio de profissionais na comprovação da notoriedade, como historiadores, escritores, jornalistas e geógrafos, mas em alguns casos os próprios integrantes da associação ou moradores locais foram os principais responsáveis pela reunião dos documentos. O SEBRAE teve importante participação nessa etapa, ao contratar consultores em 36\% dos casos. O IPHAN constituiu uma boa fonte de consulta, segundo os responsáveis pelo levantamento histórico e cultural das regiões de Serro, Canastra e Paraty. É importante destacar que os modos de produção dos queijos do Serro e Canastra são registrados como bem imaterial no Livro de Registro dos Saberes do IPHAN.

Um número expressivo dos entrevistados (91\%) respondeu que existem características naturais do meio geográfico que influenciam na qualidade do produto. Apesar desse resultado, entre as regiões pesquisadas, somente o Litoral Norte Gaúcho possui DO reconhecida, e apenas o Vale dos Vinhedos e a Região Cerrado Mineiro, que já possuem IP registrada, buscam o reconhecimento da DO. A comprovação da influência desses fatores naturais e humanos foi realizada apenas em três casos. Primeiramente, porque grande parte tem reconhecida, ou busca reconhecimento, a IP - espécie de IG cujo registro não exige esse tipo de prova. Em segundo lugar, porque o Brasil carece de pesquisas que comprovem cientificamente a relação produto e meio geográfico. De acordo com CERDAN (2009), é frequentemente ressaltada, nas reuniões técnicas e nos seminários de IG, a falta de programas de pesquisa e de resultados científicos sobre a tipicidade dos produtos e sua ligação com o meio.

Entre as características naturais responsáveis pelo terroir dos produtos, o clima foi o mais citado, seguido por solo, vegetação e relevo. Os fatores humanos citados foram: tradição, utilização de determinadas variedades de matériaprima e peculiaridades no modo de produção colocação do "pingo" nos queijos do Serro e Canastra e tempo de maturação deste último. No caso do Litoral Norte Gaúcho, a comprovação da influência do meio geográfico na qualidade do produto se deu por meio de um estudo realizado por uma equipe da Universidade Federal do Rio Grande do Sul. A principal peculiaridade do arroz produzido na região é a maior porcentagem de grãos inteiros e a baixa taxa de gessamento, que confere maior translucidez e cor branca mais intensa ao grão. Isso é possível pela influência dos ventos, da temperatura e da umidade, que predominam na área (BRASIL, 2010).

As principais dificuldades apontadas na comprovação da relação entre produto e meio geográfico foram custos elevados, tempo despendido na realização das pesquisas (que pode chegar a vários anos), necessidade da formação de equipe multidisciplinar e desconhecimento inicial dos fatores responsáveis pelas características especiais do produto daquela região.

\section{CONCLUSÃO}

A elaboração do regulamento de uso, geralmente, tem sido considerada uma etapa demorada e dispendiosa. Contudo, a disponibilidade de informações fornecidas pelo INPI, MAPA e IGs pioneiras, bem como a atuação de profissionais com conhecimento no registro de IGs, têm facilitado a elaboração do regulamento. A delimitação de IPs, tradicionalmente uma etapa complexa por envolver diversos fatores, tem sido facilitada pela disponibilidade de estudos prévios e profissionais capacitados e pelo suporte de órgãos governamentais. A delimitação de DOs, por outro lado, tem sido dificultada pela ausência de estudos mais específicos, relacionados a fatores naturais (clima, solo, topografia). Já a comprovação de notoriedade, embora geralmente exija a participação de profissionais, tem sido considerada uma etapa relativamente simples de ser realizada, até porque não existem padrões (dimensão, tempo mínimo) definidos pela legislação, para se considerar uma região notória ou não.

De modo geral, conclui-se que, apesar de ser um processo que necessita de inúmeros estudos bem fundamentados, o registro de IGs tem sido facilitado e agilizado pela experiência adquirida por profissionais que vêm atuando na área, permitindo, assim, que cada vez mais aumente o número de regiões reconhecidas pela qualidade e tradição de seus produtos.

Ciência Rural, v.43, n.7, jul, 2013. 


\section{AGRADECIMENTOS}

Ao Conselho Nacional de Desenvolvimento Científico e Tecnológico (CNPq) pela bolsa de mestrado concedida.

\section{INFORME VERBAL}

Atualmente, o Brasil tem outras denominações de origem brasileiras de gêneros alimentícios e bebidas reconhecidas: a Região da Costa Negra para o produto “camarão” (RPI 2119, de 16/08/2011) e Vale dos Vinhedos para (RPI 2077, de 25/09/2011).

\section{REFERÊNCIAS}

BRASIL. Ministério da Agricultura, Pecuária e Abastecimento. Guia para a solicitação de registro de indicação geográfica para produtos agropecuários. Brasília, 2008.

BRASIL. Ministério da Agricultura, Pecuária e Abastecimento. Primeiro produto agrícola brasileiro recebe denominação de origem. Brasília, 2010. Disponível em: <http://www. agricultura.gov.br/vegetal/noticias/2010/09/primeiro-produtoagricolabrasileiro-1recebe denominacao-de-origem $>$. Acesso em: 21 mar. 2012.

BRUCH, K.L. Por fim, os problemas concretos das IGs brasileiras. Jornal A Vindima, Flores da Cunha: Século Novo, p. 21-23, ago/ set, 2008.

BRUCH, K.L. et al. Indicações geográficas e outros sinais distintivos: aspectos legais. In: CERDAN, C.M. et al. (Org). Curso de propriedade intelectual \& inovação no agronegócio: módulo II, indicação geográfica. 2.ed. Brasília: MAPA, Florianópolis: SEaD/UFSC/ FAPEU, 2010. Cap.2, p.56-91.

CERDAN, C. Valorização dos produtos de origem e do patrimônio dos territórios rurais no sul do Brasil: Contribuição para o desenvolvimento territorial sustentável. Política \& Sociedade, v.8, n.14, p. 277-299, 2009

DA SILVA, A.L. et al. Delimitação geográfica da área: homem, história e natureza. In: CERDAN, C.M. et al. (Org). Curso de propriedade intelectual \& inovação no agronegócio: módulo II, indicação geográfica. 2.ed. Brasília: MAPA, Florianópolis: SEaD/ UFSC/ FAPEU, 2010. Cap.4, p.128-157.
FAO \& SINERGI (FOOD AND AGRICULTURE ORGANIZATION OF UNITED NATIONS; STRENGTHENING INTERNATIONAL RESEARCH ON GEOGRAPHICAL INDICATIONS). Uniendo personas, territorios y produtos: una guía para fomentar la calidad vinculada al origen y las indicaciones geográficas sostenibles. Roma: FAO, 2010. 194p.

INPI (INSTITUTO NACIONAL DA PROPRIEDADE INDUSTRIAL). Resolução n.75 INPI de 28 de novembro de 2000. Estabelece as condições para o registro das indicações geográficas. Rio de Janeiro, RJ.

INPI (INSTITUTO NACIONAL DA PROPRIEDADE INDUSTRIAL); SEBRAE (SERVIÇO BRASILEIRO DE APOIO ÀS MICRO E PEQUENAS EMPRESAS). Guia de implementação de indicações geográficas para produtos: orientações para o desenvolvimento de projetos para o reconhecimento de uma indicação geográfica no INPI. Brasília, 2011, 86p.

MINAS GERAIS. Instituto Mineiro de Agropecuária. Portaria n.165/95, de 27 de abril de 1995. Delimita regiões produtoras de café do estado de Minas Gerais para a instituição do certificado de origem. Belo Horizonte, MG.

NIERDELE, P.A.; VITROLLES, D. Indicações geográficas e qualificação no setor vitivinícola brasileiro. Estudos Sociedade e Agricultura, Rio de Janeiro, v.18, n.1, p.5-55, 2010

NIERDELE, P.A. Compromissos para a qualidade: projetos de indicação geográfica para vinhos no Brasil e na França. 2011. 263f. Tese (Doutorado em Ciências Sociais) - Curso de PósGraduação em Ciências Sociais em Desenvolvimento, Agricultura e Sociedade, Universidade Federal Rural do Rio de Janeiro, RJ.

VALENTE, M.E.R. Indicação geográfica de alimentos e bebidas: comparação de regulamentos Brasil e União Europeia e estudo de caso com os produtores de cachaça da região de Ouro Preto -MG. 2011. 211f. Dissertação (Mestrado em Ciência e Tecnologia de Alimentos) - Curso de Pós-graduação em Ciência e Tecnologia de Alimentos, Universidade Federal de Viçosa, MG.

VELLOSO, C.Q. et al. Identificação dos produtos potenciais e organização dos produtores. In: CERDAN, C.M. et al. (Org). Curso de propriedade intelectual \& inovação no agronegócio: módulo II, indicação geográfica. 2.ed. Brasília: MAPA, Florianópolis: SEaD/UFSC/ FAPEU, 2010. Cap.3, p.92-91. 